\title{
Imidazole-thiazolidinone inhibits oesophageal cancer cell proliferation via induction of apoptosis and cell cycle arrest at S phase
}

\author{
Qian Wang, Yuan Yuan, Mi Jiang, Lihua Huang, Jie Huang*, Hongyuan Shen* \\ Breast Tumor Centre, The First Hospital of Jilin University, Jilin, Changchun 130021, China
}

*For correspondence: Email: JeromeMcguireblc@yahoo.com; Tel: 0086-0431-81875382

Sent for review: 14 June 2018

Revised accepted: 11 December 2019

\begin{abstract}
Purpose: To investigate the effect of imidazole-thiazolidinone on oesophageal cancer (OC) cell proliferation, and the mechanism of action involved.

Methods: Human OC cells (HCE-6 and KYSE-1170) were cultured in Dulbecco's modified Eagle's medium (DMEM) supplemented with $10 \%$ fetal bovine serum (FBS) and $1 \%$ penicillin/streptomycin solution at $37{ }^{\circ} \mathrm{C}$ for $24 \mathrm{~h}$ in a humidified atmosphere of $5 \% \mathrm{CO}_{2}$ and $95 \%$ air. After attaining $60-70$ $\%$ confluency, the cells were treated with serum-free medium and graded concentrations of imidazolethiazolidinone (up to $160 \mu \mathrm{M}$ ) for $24 \mathrm{~h}$. Normal cell culture without imidazole-thiazolidinone served as control. Cells in logarithmic growth phase were selected and used in this study. Cell proliferation and apoptosis were assessed using 3 (4,5 dimethyl thiazol 2 yl) 2,5 diphenyl $2 \mathrm{H}$ tetrazolium bromide (MTT), and flow cytometric assays, respectively. The levels of expression of apoptosis-related proteins were determined using Western blotting.

Results: Treatment of HCE-6 and KYSE-1170 cells with imidazole-thiazolidinone for 48 h led to significant and dose-dependent reduction in their proliferation, as well as significant and dosedependent increase in the number of apoptotic cells $(p<0.05)$. Light microscopy revealed significant reduction in HCE-6 cell count, detached cells, reduced cell size and irregular cytoplasmic vacuoles. Imidazole-thiazolidinone treatment significantly and dose-dependently decreased HCE-6 and KYSE1170 cell migration, and arrested HCE-6 cell cycle at $S$ phase $(p<0.05)$. In HCE-6 cells, imidazolethiazolidinone treatment significantly and dose-dependently upregulated the expressions of cleaved caspase-3/8/9 and bax, but down-regulated bcl-2 expression significantly and dose-dependently ( $p<$ 0.05). However, metalloproteinases 2 and 9 (MMP-2 and MMP-9) expressions in HCE-6 and KYSE1170 cells were significantly and dose-dependently down-regulated by imidazole-thiazolidinone treatment $(p<0.05)$.

Conclusion: The results obtained in this study suggest that imidazole-thiazolidinone suppresses OC cell proliferation via induction of apoptosis and arrest of cell cycle at $S$ phase.
\end{abstract}

Keywords: Imidazole-thiazolidinone, Oesophageal cancer, Metastasis, Cell cycle arrest, Apoptosis

This is an Open Access article that uses a fund-ing model which does not charge readers or their institutions for access and distributed under the terms of the Creative Commons Attribution License (http://creativecommons.org/licenses/by/4.0) and the Budapest Open Access Initiative (http://www.budapestopenaccessinitiative.org/read), which permit unrestricted use, distribution, and reproduction in any medium, provided the original work is properly credited.

Tropical Journal of Pharmaceutical Research is indexed by Science Citation Index (SciSearch), Scopus, International Pharmaceutical Abstract, Chemical Abstracts, Embase, Index Copernicus, EBSCO, African Index Medicus, JournalSeek, Journal Citation Reports/Science Edition, Directory of Open Access Journals (DOAJ), African Journal Online, Bioline International, Open-J-Gate and Pharmacy Abstracts 


\section{INTRODUCTION}

Oesophageal cancer (OC), a common malignant tumor among the Chinese, arises from the oesophagus [1]. Symptoms often include difficulty in swallowing and weight loss. Oesophageal cancer (OC) is ranked eighth in the hierarchy of malignant tumors, and is the sixth leading cause of cancer-related deaths worldwide [2]. Histologically, OC is of two types: squamous cell cancer (SCC) and adenocarcinoma [3]. Squamous cell carcinoma (SCC) is prevalent among Asians, while adenocarcinoma is common among Europeans [2-4]. Risk factors for OC include smoking, high alcohol consumption, excessive consumption of red meat, and obesity [4]. The insidious nature of OC makes its diagnosis difficult [5]. Surgery, chemotherapy and radiotherapy are strategies commonly employed for OC treatment $[6,7]$. These treatment options are accompanied by poor prognosis and the patients have five years survival of less than $15 \%$ [7]. Therefore, there is urgent need for the development of novel and effective treatment for OC.

Heterocyclic compounds are widely used as synthons in drug discovery [8]. Imidazole is the structural component of several complex natural products and therapeutic molecules [9]. Compounds bearing imidazole ring exhibit varied biological and pharmacological properties such as antimicrobial, antitumor, antiviral, and antimalarial effects [10]. Studies have shown that 4-nitroimidazole-containing compounds such as pretomanid and delamanid inhibit the growth of Mycobacterium tuberculosis [11]. Delamanid is an FDA-approved drug for the treatment of patients with multidrug resistant tuberculosis (MDR-TB) [11]. Pretomanid is presently under clinical trial for the treatment of tuberculosis (TB) [11]. The aim of this study was to investigate the effect of imidazolethiazolidinone on $\mathrm{OC}$ cell proliferation, and the mechanism involved.

\section{EXPERIMENTAL}

\section{Materials}

Human OC cells (HCE-6 and KYSE-1170) were obtained from the Chinese Academy of Sciences. Fetal bovine serum (FBS) and DMEM were purchased from Gibco (USA). Annexin V/FITC kit and flow cytometer were obtained from BD Biosciences (USA). Trizol reagent was a product of Invitrogen: Thermo Fisher Scientific, Inc. (USA). Bicinchoninic acid (BCA) assay kit was purchased from Sangon Biotech Co., Ltd. (China), while polyvinylidene fluoride membranes were purchased from Roche Diagnostics (Switzerland). Enhanced Chemiluminescence (ECL) detection system was a product of Thermo Fisher Scientific Ltd. (USA).

\section{Cell culture}

The HCE- 6 and KYSE- 1170 cells were cultured in DMEM supplemented with $10 \%$ FBS and $1 \%$ penicillin/streptomycin solution at $37^{\circ} \mathrm{C}$ for $24 \mathrm{~h}$ in a humidified atmosphere of $5 \% \mathrm{CO}_{2}$ and 95 $\%$ air. After attaining 60 - $70 \%$ confluency, the cells were treated with serum-free medium and graded concentrations of imidazolethiazolidinone (up to $160 \mu \mathrm{M}$ ) for $24 \mathrm{~h}$. Normal cell culture without imidazole-thiazolidinone served as control group. Cells in logarithmic growth phase were selected and used in this study.

\section{Cell proliferation assay}

The effect of imidazole-thiazolidinone on HCE-6 and KYSE-1170 cell proliferation was assessed using MTT assay. The cells were seeded at a density of $1.5 \times 10^{5}$ cells/well in 96-well plates and cultured in DMEM for $24 \mathrm{~h}$. Then, imidazolethiazolidinone_( $0-160 \mu \mathrm{M})$ was added to the cells and incubated for $48 \mathrm{~h}$. Subsequently, 20 $\mu \mathrm{L}$ of MTT solution $(5 \mathrm{mg} / \mathrm{mL})$ was added to the wells, followed by incubation at $37{ }^{\circ} \mathrm{C}$ for $5 \mathrm{~h}$. The medium was finally replaced with $100 \mu \mathrm{L}$ of $0.1 \%$ dimethyl sulfoxide (DMSO) to completely dissolve the formazan crystals formed. The absorbance of the samples was read in a microplate reader at $562 \mathrm{~nm}$. The assay was performed in triplicate, and cell proliferation (c) calculated as shown in Eq 1.

$C(\%)=(A e / A c) 100 \ldots \ldots \ldots . .(1)$

where $\mathrm{Ae}$ and $\mathrm{Ac}$ are the absorbance values for experimental and control groups, respectively.

\section{Assessment of morphological changes in OC cells}

The HCE- 6 and KYSE- 1170 cells were seeded in 12-well plates at a density of $1.5 \times 10^{6}$ cells/well and cultured in DMEM for $48 \mathrm{~h}$. Then, imidazole-thiazolidinone $(40,80$ and $160 \mu \mathrm{M})$ was added to the cells and incubated for $72 \mathrm{~h}$. After incubation, the cells were stained in the dark with $1 \mu \mathrm{g} / \mathrm{mL}$ solution of Hoechst 3325 at $37^{\circ} \mathrm{C}$ for $25 \mathrm{~min}$. The phosphate-buffered saline (PBS)-washed cells were subsequently examined for morphological alterations using fluorescent microscope. 


\section{Cell migration assay}

Changes in migratory potential of imidazolethiazolidinone-treated HCE-6 cells were determined using wound-healing assay. Cells in logarithmic growth phase were seeded in 12well plates until they attained $100 \%$ confluency, and scratches were made on the cell monolayers. The cells $\left(2.5 \times 10^{5}\right.$ cells/well $)$ were then incubated with imidazole-thiazolidinone at concentrations of 40,80 and $160 \mu \mathrm{M}$ for $48 \mathrm{~h}$ at $37^{\circ} \mathrm{C}$. After washing thrice with serum-free medium, the cells were further cultured for $24 \mathrm{~h}$, and then observed and photographed.

\section{Cell-cycle analysis}

The effect of imidazole-thiazolidinone on cell cycle distribution was determined using a flow cytometer. The HCE- 6 cells treated with varied concentrations of imidazole-thiazolidinone (40, 80 and $160 \mu \mathrm{M}$ ) were seeded into 6-well plates and incubated for $72 \mathrm{~h}$. The cells were then washed with PBS, and fixed with $70 \%$ ethyl alcohol at $4^{\circ} \mathrm{C}$ overnight. Tris-hydrochloride buffer $(\mathrm{pH} 7.5)$ containing $1 \%$ RNase $A$ was then added to the plates. The cells were subsequently stained with $50 \mu \mathrm{g} / \mathrm{mL}$ propidium iodide for $45 \mathrm{~min}$ at $37^{\circ} \mathrm{C}$ in the dark and injected into the flow cytometer for analysis.

\section{Western blotting}

The HCE- 6 and KYSE- 1170 cells $\left(5 \times 10^{8}\right.$ cells/L) were incubated with imidazolethiazolidinone for $72 \mathrm{~h}$. The cells were then washed twice with PBS and lysed with $250 \mu \mathrm{L}$ of ice-cold radio-immunoprecipitation assay (RIPA) buffer containing $0.1 \%$ sodium dodecyl sulphate (SDS), 1X PBS, $1 \%$ NP40, ethylenediamine tetraacetate, $0.5 \%$ sodium deoxycholate, $1 \%$ PMSF, protease and phosphatase inhibitors. The resultant lysate was centrifuged at 12,000 rpm for $20 \mathrm{~min}$ at $4{ }^{\circ} \mathrm{C}$, and the protein concentration of the supernatant was determined using BCA method. A portion of total cell protein $(10 \mu \mathrm{g})$ from each sample was separated on $10 \%$ SDS-polyacrylamide gel electrophoresis and transferred to a fixed polyvinylidene fluoride membrane at $110 \mathrm{~V}$ and $90{ }^{\circ} \mathrm{C}$ for $120 \mathrm{~min}$. Subsequently, non-fat milk powder (5\%) in Tris-buffered saline containing $0.2 \%$ Tween-20 (TBS-T) was added with gentle shaking at $37{ }^{\circ} \mathrm{C}$ and incubated to block nonspecific binding of the blot. Incubation of the blots was performed overnight at $4{ }^{\circ} \mathrm{C}$ with primary antibodies of rabbit polyclonal anti-bax, anti-bcl-2, anti-caspase-3/8/9, anti-MMP-2, antiMMP-9 and anti- $\beta$-actin, each at a dilution of 1 to 800 . Then, the membrane was washed thrice with PBS and further incubated with horseradish peroxidase-conjugated goat anti-rabbit $\operatorname{lgG}$ secondary antibody for $1.5 \mathrm{~h}$ at room temperature. The blot was developed using an X-ray film. Grayscale analysis of the bands was performed using ECL. The respective protein expression levels were normalized to that of $\beta$ actin which was used as a standard.

\section{Statistical analysis}

Data are expressed as mean \pm SD. Statistical analysis was performed using SPSS (version 16.0). Groups were compared using Student's $t$ test. Statistical significance was assumed at $p<$ 0.05 .

\section{RESULTS}

\section{Effect of imidazole-thiazolidinone on OC cell proliferation}

As shown in Figure 1, treatment of HCE-6 and KYSE-1170 cells with imidazole-thiazolidinone for $48 \mathrm{~h}$ led to significant and dose-dependent reductions in their proliferation $(p<0.05)$. The proliferation of HCE-6 cell was reduced from 94 to $33 \%$, while KYSE-1170 cell proliferation decreased from 96 to $37 \%$.

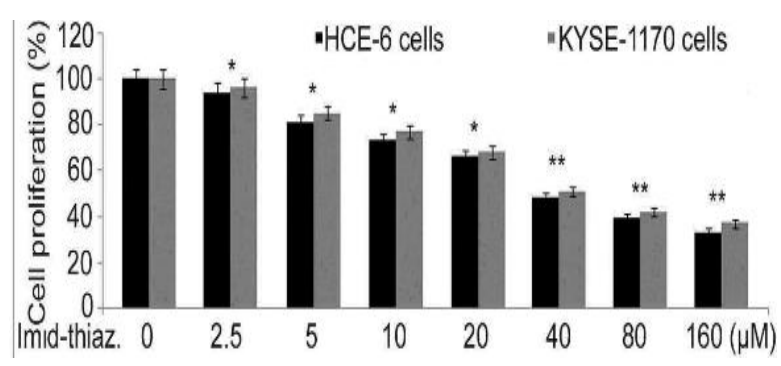

Figure 1: Effect of imidazole-thiazolidinone on OC cell proliferation. ${ }^{*} p<0.05$ and ${ }^{* *} p<0.01$, when compared with control cells

\section{Morphological alterations in HCE-6 cells after treatment with imidazole-thiazolidinone}

Light microscopic examination revealed significant reductions in HCE-6 cell count, detached cells, reduced cell size and irregular cytoplasmic vacuoles after treatment with imidazole-thiazolidinone. However, the control cells were polygonally shaped, with marked borders and exponential growth. There were obvious apoptotic changes in HCE- 6 cell cultures treated with graded concentrations of imidazole-thiazolidinone. These results are shown in Figure 2. 


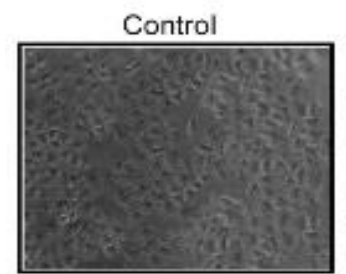

$80(\mu \mathrm{M})$
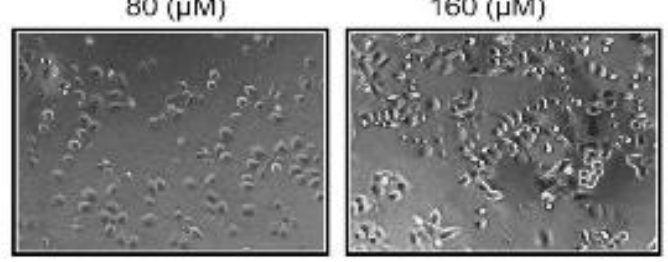

Figure 2: Effect of imidazole-thiazolidinone on HCE-6 cell morphology (x 200)

\section{Effect of imidazole-thiazolidinone on OC cell migration}

Imidazole-thiazolidinone treatment significantly and dose-dependently decreased the migrations of HCE- 6 and KYSE-1170 cells $(p<0.05)$. In HCE- 6 cells, migration decreased from 51.32 to $6.31 \%$, while that of KYSE-1170 cells was reduced from 56.14 to $11.87 \%$ (Figure 3 ).

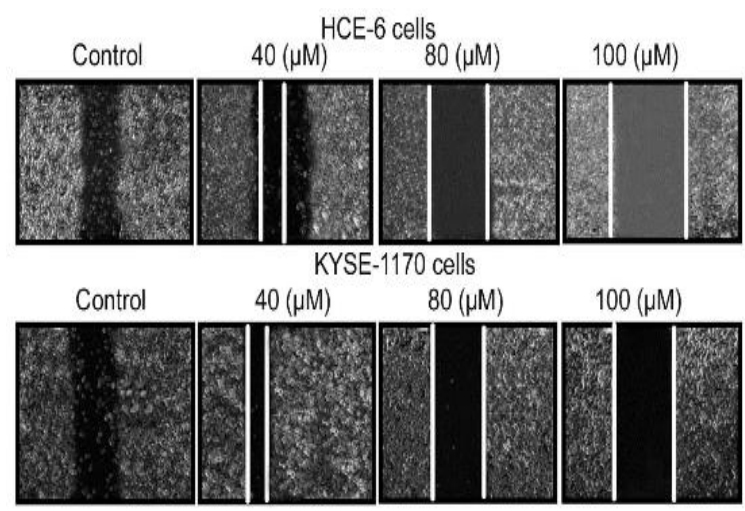

Figure 3: Effect of imidazole-thiazolidinone on OC cell migration

\section{Effect of imidazole-thiazolidinone on HCE-6 cell cycle arrest}

Imidazole-thiazolidinone treatment significantly and dose-dependently increased the population of HCE- 6 cells in S phase $(p<0.05)$. The HCE6 cell population in $S$ phase increased from 13.56 to $27.14 \%$. The HCE-6 cell population in G1/G0 and G2/M phases were significant reduced, relative to control group $(p<0.05)$. Treatment of HCE-6 cells with imidazolethiazolidinone significantly arrested HCE-6 cell cycle at $S$ phase. These results are shown in Figure 4.

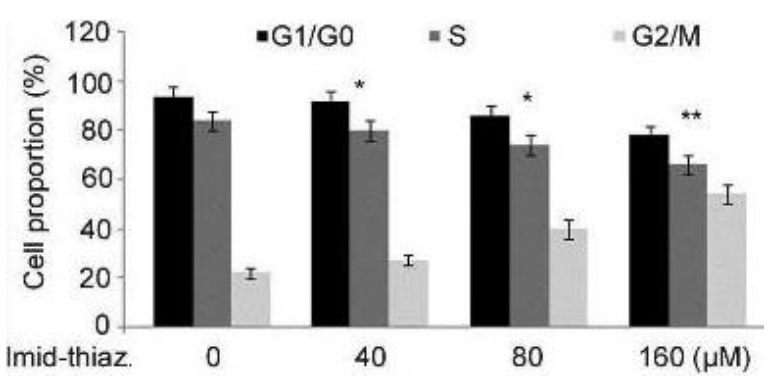

Figure 4: Effect of imidazole-thiazolidinone on HCE-6 cell cycle arrest; ${ }^{*} p<0.05$, when compared with control cells

\section{Expressions of apoptosis-related proteins in OC cells}

In HCE-6 cells, imidazole-thiazolidinone treatment significantly and dose-dependently upregulated the expressions of cleaved caspase-3/8/9 and bax, but down-regulated bcl2 expression significantly and dose-dependently $(p<0.05)$. However, MMP-2 and MMP-9 expressions in HCE- 6 and KYSE-1170 cells were significantly and dose-dependently downregulated by imidazole-thiazolidinone treatment $(p<0.05$; Figure 5).

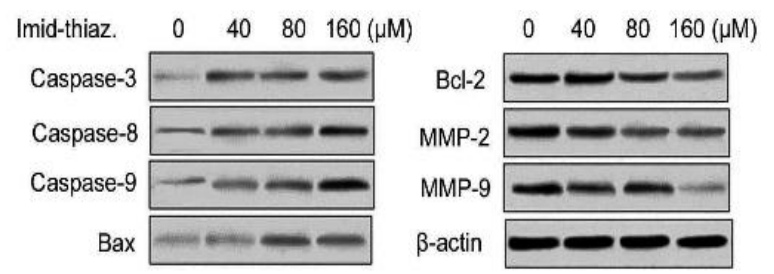

Figure 5: Effect of imidazole-thiazolidinone treatment on the levels of expression of apoptosis-related proteins in OC cells

\section{DISCUSSION}

Oesophageal cancer (OC), a common malignant tumor among the Chinese, arises from the oesophagus [1]. Symptoms often include difficulty in swallowing and weight loss. Imidazole is the structural component of several complex natural products and therapeutic molecules [9]. Compounds bearing imidazole ring exhibit varied biological properties such as antimicrobial, antitumor, antiviral, and antimalarial effects [10]. This study investigated the effect of imidazole-thiazolidinone on OC cell proliferation, and the mechanism involved.

Cancer cells are characterized by uncontrolled proliferation. Thus, regulation of cell growth is vital in cancer treatment [12].

In this study, imidazole-thiazolidinone treatment significantly and dose-dependently inhibited OC 
cell proliferation. These results are in agreement with those of previous reports [13]. Studies have shown that cell cycle progression is closely associated with increased cell proliferation. Each phase of the cell cycle is regulated by checkpoint proteins which control transition from one phase to another [13]. Failure of any of the checkpoints leads to uncontrolled cell division and ultimately cancer [14].

Cell cycle arrest forms the basis for inhibition of cancer cell proliferation [15]. In this study, imidazole-thiazolidinone treatment led to arrest of HCE-6 cell cycle at S phase. In imidazolethiazolidinone-treated cell cultures, the proportion of HCE-6 cells in $S$ phase was markedly increased, but reduced in G1/G0 and G2/M phases. The highly regulated process of apoptosis is responsible for elimination of unwanted cells from an organism [16]. Apoptosis activation involves the secretion of caspases, with caspase- 3 being the most important [17].

Activation of bax is usually accompanied by increased mitochondrial membrane permeability and cytochrome $c$ efflux into the cytoplasm [17]. Cytochrome $c$ plays a key role in the activation of caspase- 9 which is required for induction of apoptosis [17]. Therefore, activation of the apoptotic pathway by chemotherapeutic agents is a major consideration in cancer treatment [18]. In this study, imidazole-thiazolidinone treatment significantly and dose-dependently upregulated the expressions of cleaved caspases-3/8/9 and bax, while down-regulating bcl-2 protein expression in OC cells. It is likely that imidazole-thiazolidinone regulates HCE-6 and KYSE-1170 cell proliferation via induction of apoptosis. During metastasis, cancer cells invade the lymph and blood vessels, thereby spreading to nearby organs [19]. In more than $50 \%$ of patients, OC is detected at the metastatic stage which is characterised by poor prognosis [20]. Studies have shown that the levels of extracellular matrix proteins and degree of cell metastasis are key in cancer treatment [21]. In this study, imidazole-thiazolidinone treatment significantly inhibited the migration and invasiveness of HCE-6 cells. It also significantly and dose-dependently downregulated the expressions of MMP-2 and MMP-9 in HCE-6 and KYSE-1170 cells.

\section{CONCLUSION}

The results obtained in this study suggest that imidazole-thiazolidinone suppresses OC cell proliferation via induction of apoptosis and arrest of cell cycle at $S$ phase. Therefore, the compound has potentials for development into an agent for the treatment of oesophageal cancer.

\section{DECLARATIONS}

\section{Conflict of interest}

No conflict of interest is associated with this work.

\section{Contribution of authors}

We declare that this work was done by the authors named in this article and all liabilities pertaining to claims relating to the content of this article will be borne by the authors. Qian Wang, Yuan Yuan and $\mathrm{Mi}$ Jiang performed the experimental work. Lihua Huang and Hongyuan Shen carried out the literature survey and analysed the data. Jie Huang compiled the data and designed the study. All the authors wrote and approved the paper for publication.

\section{Open Access}

This is an Open Access article that uses a funding model which does not charge readers or their institutions for access and distributed under the terms of the Creative Commons Attribution License (http://creativecommons.org/licenses/by/ 4.0) and the Budapest Open Access Initiative (http://www.budapestopenaccessinitiative.org/rea d), which permit unrestricted use, distribution, and reproduction in any medium, provided the original work is properly credited.

\section{REFERENCES}

1. Chen $W$, Zheng $R$, Zeng $H$, Zhang $S$. The incidence and mortality of major cancers in China, 2012. Chin $J$ Cancer 35: 732016.

2. Jemal A, Bray F, Center MM, et al. Global cancer statistics. CA Cancer J Clin 2011; 61: 6990.

3. Cook MB, Chow WH, Devesa SS. Oesophageal cancer incidence in the United States by race, sex, and histologic type, 1977 2005. Br J Cancer 2009; 101: 855 859.

4. Rubenstein JH, Chen JW. Epidemiology of gastroesophageal reflux disease. Gastroenterol Clin North Am 2014; 43: 114.

5. Gaur P, Kim MP, Dunkin BJ. Esophageal cancer: Recent advances in screening, targeted therapy, and management. J Carcinog 2014; 13: 11.

6. Tepper J, Krasna MJ, Niedzwiecki D, Reed CE, Goldberg $R$, Kiel K, Willett C, Sugarbaker D, Mayer R. Phase III trial of trimodality therapy with cisplatin, fluorouracil, radiotherapy, and surgery compared with surgery alone 
for esophageal cancer: CALGB 9781. J Clin Oncol 2008; 26: 1086-1092.

7. Blazeby JM, Farndon JR, Donovan J, Alderson D. A prospective longitudinal study examining the quality of life of patients with esophageal carcinoma. Cancer 2000; 88: 1781-1787.

8. Zhang $\mathrm{HZ}$, Zhao $\mathrm{ZL}$, Zhou $\mathrm{CH}$. Recent advance in oxazole-based medicinal chemistry. Eur J Med Chem 2018; 144: 444-492.

9. Akhtar J, Khan AA, Ali Z, Haider R, Yar MS. Structureactivity relationship (SAR) study and design strategies of nitrogen-containing heterocyclic moieties for their anticancer activities. Eur J Med Chem 2017; 125: 143189.

10. Xu Z, Gao C, Ren QC, Song XF, Feng LS, Lv ZS. Recent advances of pyrazole-containing derivatives as antitubercular agents. Eur J Med Chem 2017; 139: 429-440.

11. Zhong YJ, Shi F, Zheng XL, Wang Q, Yang L, Sun H, He $F$, Zhang L, Lin $Y$, Qin $Y$, Liao LC, Wang $X$. Crocetin induces cytotoxicity and enhances vincristine induced cancer cell death via p53 dependent and independent mechanisms. Acta Pharmacol Sin 2011: 32: 15291536.

12. Dehay C, Kennedy H. Cell-cycle control and cortical development. Nat Rev Neurosci 2007; 8: 438-450.
13. Kastan MB, Bartek J. Cell-cycle checkpoints and cancer. Nature 432: 316-323, 2004.

14. Chu G. Cellular responses to cisplatin. The roles of DNAbinding proteins and DNA repair. J Biol Chem 1994; 269: 787-790.

15. Warner TF. Apoptosis. Lancet 1972; 2: 1252.

16. Li $P$, Nijhawan $D$, Wang $X$. Mitochondrial activation of apoptosis. Cell 2004; 116 (Suppl 2): S57 S59.

17. Wyllie $A H$. The biology of cell death in tumours. Anticancer Res 1985; 5: 131-136.

18. Napier KJ, Scheerer M, Misra S. Esophageal cancer: $A$ review of epidemiology, pathogenesis, staging workup and treatment modalities. World $J$ Gastrointest Oncol 2014; 6: 112-120.

19. Javle M, Ailawadhi S, Yang GY, Nwogu CE, Schiff MD, Nava HR. Palliation of malignant dysphagia in esophageal cancer: a literature-based review. J Support Oncol 2006; 4: 365 373, 379.

20. Martin TA. The role of tight junctions in cancer metastasis. Semin Cell Dev Biol 2014; 36C: 224-231.

21. Liotta LA, Rao CN, Barsky SH. Tumor invasion and the extracellular matrix. Lab Invest 1983; 49: 636-649. 